\title{
Plasticity in oviposition and foraging behavior in the invasive pest Drosophila suzukii across natural and agricultural landscapes
}

\author{
Johanna Elsensohn ${ }^{1}$ and Hannah Burrack ${ }^{2}$ \\ ${ }^{1}$ USDA Agricultural Research Service \\ ${ }^{2}$ North Carolina State University
}

October 6, 2021

\begin{abstract}
1. Context and need for work The effects and extent of the impacts of agricultural insect pests in and around cropping systems is a rich field of study. However, little research exists on the presence and consequence of pest insects in undisturbed landscapes distant from crop hosts. Research in such areas may yield novel or key insights on pest behavior or ecology that is not evident from agroecosystem-based studies. 2. Approach and methods Using the invasive fruit pest Drosophila suzukii (Matsumura) as a case study, we investigated the presence and resource use patterns of this agricultural pest in wild blackberries growing within the southern Appalachian Mountain range of North Carolina over two years. 3. Main results We found D. suzukii throughout the sampled range with higher levels of infestation (D. suzukii eggs/g fruit) in all ripeness stages in natural areas as compared to cultivated blackberry samples, but especially in under-ripe fruit. 4. Main results We also explored a direct comparison of oviposition preference between wild and cultivated fruit and found higher oviposition in wild berries when equal weights of fruit were offered, but oviposition was higher in cultivated berries when fruit number was equal. 5. Synthesis and applications D. suzukii were wide-spread in previously unsampled remote, forest habitats. Forest populations laid more eggs in unripe wild-grown blackberries throughout the year than populations infesting cultivated berries. This suggests $D$. suzukii may change its oviposition and foraging behavior in relation to fruit type. Additionally, as D. suzukii exploits a common forest fruit prior to ripeness, further research is needed to explore how this affects wild food web dynamics and spillover to regional agroecosystems.
\end{abstract}

Johanna E. Elsensohn

USDA-ARS Appalachian Fruit Research Station

2217 Wiltshire Road

Kearneysville, WV 25430 USA

1.860.367.7009 | j.elsensohn@gmail.com

Title: Plasticity in oviposition and foraging behavior in the invasive pest Drosophila suzukii across natural and agricultural landscapes

Authors: Johanna E. Elsensohn ${ }^{1,2,3}$ and Hannah J. Burrack ${ }^{1}$

${ }^{1}$ Department of Entomology and Plant Pathology, North Carolina State University, Raleigh, NC

${ }^{2}$ Current affiliation: USDA-ARS Appalachian Fruit Research Station, Kearneysville, WV

${ }^{3}$ Corresponding author details above title

\section{Abstract}


1. Context and need for work The effects and extent of the impacts of agricultural insect pests in and around cropping systems is a rich field of study. However, little research exists on the presence and consequence of pest insects in undisturbed landscapes distant from crop hosts. Research in such areas may yield novel or key insights on pest behavior or ecology that is not evident from agroecosystem-based studies.

2. Approach and methods Using the invasive fruit pest Drosophila suzukii (Matsumura) as a case study, we investigated the presence and resource use patterns of this agricultural pest in wild blackberries growing within the southern Appalachian Mountain range of North Carolina over two years.

3. Main results We found D. suzukii throughout the sampled range with higher levels of infestation (D. suzukiieggs/g fruit) in all ripeness stages in natural areas as compared to cultivated blackberry samples, but especially in under-ripe fruit.

4. Main results We also explored a direct comparison of oviposition preference between wild and cultivated fruit and found higher oviposition in wild berries when equal weights of fruit were offered, but oviposition was higher in cultivated berries when fruit number was equal.

5. Synthesis and applications D. suzukii were wide-spread in previously unsampled remote, forest habitats. Forest populations laid more eggs in unripe wild-grown blackberries throughout the year than populations infesting cultivated berries. This suggests D. suzukii may change its oviposition and foraging behavior in relation to fruit type. Additionally, as D. suzukii exploits a common forest fruit prior to ripeness, further research is needed to explore how this affects wild food web dynamics and spillover to regional agroecosystems.

Key words: forest, non-native species, crop domestication

\section{Introduction}

The niche breadth of polyphagous insect pests can be expansive due to a number of biological and abiotic factors including the ability to exploit diverse host types in heterogenous environments and the capacity to respond to changing conditions over time (Kennedy \& Storer 2000, Sakai et al. 2001, Little et al. 2020). Species with broad host ranges also tend to have an outsized impact on crops as compared to monophagous or oligophagous insect species (Ward and Spalding 1993). It is reasonable to assume these substantial impacts may also occur in non-crop areas. Considerable research has been conducted in semi-natural lands adjacent to or near affected crops, as these are the areas thought to be highly influential to agroecosystem dynamics (Kennedy and Storer 2000, Rand et al. 2006, Mazzi and Dorn 2012).

For polyphagous pests, non-crop host plants occur throughout the landscape, including places far removed from agriculture. These areas, such as forests, are rarely assessed for the presence of agricultural insect pests unless they are also considered a forest pest, such as pear thrips, Taeniothrips inconsequens (Uzel) (Teulon et al. 1998), or the spotted lanternfly, Lycorma deliculata White (Barringer and Ciafré 2020). Nevertheless, studying non-forest crop pests in remote areas might be important for a number of reasons. First, these insects may impact forest food web dynamics through resource use competition of common host plants. Second, if these remote locations host established populations of agricultural pests, then they may be a source for seasonal migrants into cultivated areas. Third, understanding pest behavior outside of the agroecosystem may yield novel insights into pest behavior and ecology that may not be evident in highly human-influenced agricultural areas. Finally, such insights can then be used to improve modeling predictions for current and future range expansions.

Distribution modeling is a common way to model invasive species and is based on known life history traits and occurrence. However, ground truthing to inform or verify model-based inferences (e.g., likelihood of occurrence or density) often fails to venture outside of areas where the pest is causing direct economic damage, namely cropland in this case. Failure to fully verify these distribution models limits their usefulness and insight (Wright et al. 2006, Fitzpatrick et al. 2007, Sarquis et al. 2018). Furthermore, niche divergence may occur more readily in areas with more diverse habitat and can be indicative of ecological changes such as invasive species establishment, food web disruption, or climate change (Wright et al. 2006). 
Drosophila suzukii (Matsumura) is a highly cosmopolitan agricultural pest of berry crops. Native to East Asia, D. suzukiiwas limited in spread until 2008 when accidental introductions led to a range expansion into Europe and continental North America, and in subsequent years to South America, Western Asia and most recently in Africa (Hauser et al. 2011, Calabria et al. 2012, Deprá et al. 2014, Parchami-Araghi et al. 2015, Hassani et al. 2020). Ripe fruit from cultivated berry crops and wild-growing native and non-native plant species serve as oviposition sites for female D. suzukii and nutritional resources for all life stages. The presence and movement of this fly has been well-studied in croplands and nearby disturbed or wooded areas that serve as potential refuge sites and often contain susceptible hosts (Bellamy et al. 2013, Lee et al. 2015, Klick et al. 2016, Elsensohn and Loeb 2018, Santoiemma et al. 2018). Some host plant species are regionally common and can be found well outside agroecosystems, including in backyards, roadsides, woods, and fields, among other places (e.g., Mitsui et al. 2010, Poyet et al. 2014, Ballman and Drummond 2017).

Several ecological models were created to assess the current and future distribution of D. suzukii around the world (Gutierrez et al. 2016, dos Santos et al. 2017, Fraimout and Monnet 2018, de la Vega and Corley 2019, Ørsted and Ørsted 2019). One species distribution model using global occurrence data indicated a higher likelihood of occurrence in the southern Appalachian Mountains of the eastern United States than in surrounding areas (Ørsted and Ørsted 2019). Contrastingly, a physiologically-based demographic model estimated a lower D. suzukii density in the same area (Gutierrez et al. 2016). Much of this region of the Appalachian Mountains, which ranges in elevation from $900-1850 \mathrm{~m}$, is designated as federally protected National Forest land. No commercial plantings of cultivated D. suzukii hosts are known to occur within this area, although D. suzukii -susceptibleVaccinium and Rubus spp. native to North America grow well here (Powell and Searman 1990).

To date, no studies have sought to ground truth model-predicted occurrence sites sparsely populated by humans as potential population sources of D. suzukii. In Europe, altitudinal studies demonstrated an established presence of D. suzukii in high elevation, mountainous locations (Tait et al. 2018, Santoiemma et al. 2019), and documented recapturing marked adults over $9 \mathrm{~km}$ from the release site (Tait et al. 2018). This distance is suggestive of weather-assisted movement, as flight mill tests show the flight capacity of adults is less than $2 \mathrm{~km}$ (Wong et al. 2018). Insect dispersal through wind patterns is documented in several pest species (Hoelscher 1967, Compton 2002, Moser et al. 2009) and has been postulated as a potential means of yearly recolonization by D. suzukii at northern U.S. latitudes after winter temperatures kill the vast majority of overwintering flies (Rossi-Stacconi et al. 2016, Panel et al. 2018, Wallingford et al. 2018). Localized $D$. suzukii movement from shrubby or wooded landscapes into crop fields is well documented (Klick et al. 2016, Pelton et al. 2016, Tonina et al. 2018). Uncultivated and cultivated areas can be exploited concurrently or consecutively throughout the year, especially in areas where adults are caught year-round (Ballman and Drummond 2017, Elsensohn and Loeb 2018, Santoiemma et al. 2018). Uncultivated areas can enlarge or sustain pest populations that could spill back into crop areas through short or long-distance movement, and vice versa.

Some non-crop hosts may be preferred oviposition sites for female $D$. suzukii or offer better nutritional resources needed for larval development. Comparative work exploring oviposition preference between crop and non-crop host species found that preference depended on the specific fruit combinations used (Lee et al. 2015, Diepenbrock et al. 2016). The first direct comparison of D. suzukii oviposition preference between wild and cultivated fruit of the same crop type found that females laid more eggs into cultivated than wild blueberries (Rodriguez-Saona et al. 2019). However, these results may be confounded by differences in fruit size, weight, and surface area between domesticated and wild relatives.

Laboratory research into oviposition preference as a factor of fruit ripeness stage revealed that the ripe stage was the most preferred for oviposition while progressively under-ripe stages received fewer or no eggs (Lee et al. 2011, Kamiyama and Guédot 2019). In a field setting, fewer adults emerged from blackberry fruit infested during under-ripe stages than fruit infested later at the ripe stage (Swoboda-Bhattarai and Burrack 2017). These results align with laboratory studies that show a survival hierarchy with ripe fruit producing the lowest mortality rate (Lee et al. 2011, Bernardi et al. 2017, Kamiyama and Guédot 2019). 
To better understand D. suzukii oviposition preference and general resource use in areas unaffected by spillover dynamics, we conducted an elevational gradient study in the southern Appalachian Mountain region. Here, modeling predictions are uncertain, but non-crop hosts are common. Over two years, we visited three natural areas and one roadside tract surrounded by National Forest lands in western North Carolina to collect wild-growing fruit at different stages of ripeness. The main objectives of this study were to: 1 ) document the presence or absence of $D$. suzukii in the unpopulated areas; 2) compare seasonal host use patterns of wild and cultivated blackberry fruits; and 3) assess host preference between wild and crop fruit in a laboratory setting.

\section{Methods}

\section{Field Collections}

We visited four locations in North Carolina where large wild blackberry stands ( $>15$ canes/10m) were established: Southern Nantahala Forest in Macon County; Cherokee National Forest in Avery County, and Joyce Kilmer -Slickrock Wilderness Area (JKWA) and along the Cherohala Skyway in Graham County (Supplementary Table S1). Required permits to sample in these places were obtained from the appropriate agencies. Sampling sites were determined by location and density of blackberry plants and separated by a distance of at least $1 \mathrm{~km}$. Fruit collection began when fruit appeared almost full size (subjectively determined by drupelet size) but were still green. Sites were resampled every 2-3 weeks until no ripe fruit were available.

At each site, blackberry plants within a radius of $10 \mathrm{~m}$ were sampled for fruit at the following ripeness stages: green, blush (reddish green), red, purple, and ripe. Two research station plantings of cultivated blackberries were sampled during the same week as wild collections, but only ripe fruit were collected at research farms after the first visit due to low fruit set that year. Up to 20 fruit of each stage were sampled at each site as available, grouped in breathable bags, and transported to the lab in a cooler $\left(4^{\circ} \mathrm{C}\right)$. Fruits were collectively weighed by sample group and examined under a dissecting microscope for the number of $D$. suzukii eggs laid per berry. Drosophila suzukii eggs were distinguished from other potential fruit-infesting flies by observing and counting the number of respiratory filaments per oviposition site (Hauser et al. 2011). Although Drosophila melanogaster and D. simulans eggs also possess only two filaments per egg, we collected fruits before they were susceptible to oviposition by these two species. Other plant species growing adjacent to blackberry plants with ripe fruit that appeared susceptible toD. suzukii were collected at random and similarly checked for infestation. All plant species were identified using Weakley (2006).

\section{Field Collections}

JKWA was chosen as the focal wild fruit collection location in 2018. Wild blackberries were collected along a trail approximately every $50 \mathrm{~m}$ change in elevation at five locations along a single trail [1430-1630 m] (Supp. Table S1). We could only utilize one research station planting in 2018 because the other planting was removed at the end of the 2017 growing season. However, all ripeness stages were assessed for infestation at this location, as available. All other sampling methods remained the same as in the previous year.

\section{Oviposition preference}

Exclusion netting (a mesh bag approximately100 x150 mm) was placed around single infructescences after petal fall in both years on wild and cultivated blackberry bushes. Netting bags were secured at the base of the cluster with a foam strip encircled by a plastic zip tie to ensure a tight seal to prevent insect entry but not damage the plant. Fruit were monitored, and when ripe fruit were observed in both cultivation types, all netted, ripe berries were collected at a single wooded and cultivated site on the same day and brought back to the lab. The following day, fruit were examined under a microscope to verify a lack of insect or mechanical damage. A two-choice bioassay was set up using equal weights of cultivated and wild blackberries placed in $35 \times 10 \mathrm{~mm}$ petri dishes in the bottom of a $473-\mathrm{ml}$ plastic container. Two 5-7-day old females from the laboratory colony (see Hardin et al. 2015) were added to the container and removed after 90 minutes and the number of eggs per berry was counted. A separate two-choice assay compared oviposition preference between a single cultivated and single wild blackberry fruit using the same protocol. 


\section{Statistical analysis}

Data were analyzed using SAS v. 9.4 (SAS Institute, Cary, NC). Samples that comprised fewer than 10 fruits were excluded from the analysis. Week represents time after the first sample was collected and held constant for both years. Cultivation type denotes whether the berry was wild-grown or cultivated. Eggs per berry are the mean number of eggs per fruit while eggs per gram were calculated using the number of eggs per berry divided by the average per berry weight of each sample group. The eggs per gram value was log transformed to adjust for assumptions of normality. Unless noted otherwise, we used a generalized mixed model (GLIMMIX) with a log normal distribution. Adjusted means were compared using the Tukey-Kramer adjustment.

In order to examine average infestation by cultivation type and ripeness stage, ripeness stage and cultivation type were considered fixed effects, and year, elevation nested within year, location, and week nested within year as random effects. For weekly infestation rates, eggs per gram was used as the dependent variable, week, ripeness stage and cultivation type were considered fixed effects, and year, location, and berry nested in location by week were random effects.

The effect of elevation was assessed for JKWA samples from 2018 with elevation, ripeness stage and week as fixed effects. The proportion of infested fruit at each sampling point (ripeness stage/location/week) was calculated as the number of berries with one or more eggs divided by the total number of berries in that sample group. Data were fitted to a normal distribution via Proc GLIMMIX with cultivation type, ripeness stage, and their interaction as fixed effects and location, year, and elevation nested within location as random effects.

Oviposition preference was calculated as the proportion of eggs laid in either the wild or cultivated berries divided by the total number of eggs laid in each replicate. These proportion data were then evaluated with a paired Student t-test; replicates with non-responding flies (those which did not lay eggs during the experimental period) were removed from analysis.

\section{Results}

\section{Field infestation}

Both ripeness stage and cultivation type had a significant effect on the number of eggs per berry (Fig. 1a; ripeness stage* ${ }^{*}$ cultivation type: $\mathrm{p}<0.0001, \mathrm{~F}_{3,1951}=69.72$, GLIMMIX). In both years, cultivated ripe and purple berries carried more eggs than wild berries at the same ripeness stage, while infestation in red, blush and green berries were more similar. However, cultivated berries on average were 3-4-fold the weight of wild ones, and after accounting for weight, wild berries contained more eggs per gram than cultivated berries at all ripeness stages (Fig. $1 \mathrm{~b}$; ripeness stage*cultivation type: $\mathrm{p}<0.0001, \mathrm{~F}_{3,1786}=9.08$ ).

There was a three-way interaction effect of ripeness stage, week, and cultivation type on infestation per gram of fruit over time (ripeness stage* ${ }^{*}$ week $^{*}$ cultivation type: $\mathrm{p}=0.01, \mathrm{~F}_{7,1759}=2.52$, GLIMMIX). Cultivated berries appeared to maintain a consistent infestation pattern throughout the season, with ripe fruit containing the most eggs and the blush stage (least ripe stage collected) having the fewest eggs (Fig. 2a). In contrast, the correlation between infestation and ripeness stage in wild fruit is much less clear (Fig. 2b), even though ripeness overall was a significant factor (ripeness stage: $\mathrm{p}<0.0001, \mathrm{~F}_{4,1759}=91.81$ ). We sampled two habitat types (woods and roadside) for wild-growing berries, and unexpectedly the average infestation between the two types were similar (Supp. Table S2).

Focusing only on the 2018 wild fruit samples collected at different elevations, effects from elevation and ripeness stage were each significant (elevation: $\mathrm{p}<0.0001, \mathrm{~F}_{4,851}=6.21$; ripeness stage: $\mathrm{p}<0.0001, \mathrm{~F}_{4,851}$ $=40.48$, GLIMMIX), but their interaction was not, suggesting that all elevations were infested to a similar degree (elevation*ripeness stage: $\mathrm{p}=0.35, \mathrm{~F}_{12,851}=1.11$ ). There is evidence for differential timing of infestation, as the three-way interaction among all variables was significant (Fig. 3; elevation*ripeness stage* week: $\left.\mathrm{p}=0.002, \mathrm{~F}_{13,851}=2.49\right)$. Lower elevations had available fruit for collection two weeks before higher elevations. In general, the only significant differences between ripeness stages within each elevation was between 
the blush and ripe stage, otherwise mean infestations were not significantly different.

To examine differences in the pattern of infestation among sample types, we calculated the percentage of berries that contained at least one egg per sample group. Ripe and purple wild berries and ripe cultivated berries had above a 95\% mean infestation across all timepoints (Table 1). Cultivated and wild fruits of the same ripeness stage (cultivation type: $\mathrm{p}=0.0625, \mathrm{~F}_{1,55}=3.61$ ) were not significantly different from each other, although green wild and blush fruits of both types were significantly less infested overall than those at the ripe stage (cultivation type*ripeness stage: $\mathrm{p}<0.0001, \mathrm{~F}_{3,55}=8.62$ ). A weekly breakdown shows near $100 \%$ infestation in wild ripe and purple fruits throughout the sampling period, but more variable infestation in fruit at earlier ripeness stages (Supp. Fig. S1). Sampling other wild-growing fruits found near wild blackberry canes revealed a range of infestation patterns (Table S3). Plant species phylogenetically close to known $D$. suzukiihost plants were more likely to be infested than those more distant phylogenetically.

\section{Oviposition preference}

When exposed to equal masses of cultivated and wild blackberries, laboratory-reared female D. suzukii laid more eggs in wild fruit (Fig. 4; $0.80 \pm 0.05$ SEM for wild, $0.20 \pm 0.05$ for cultivated; $\mathrm{p}<0.0001, \mathrm{t}_{13}=5.72$, Student t-test). The number of wild berries per replicate varied (1-9 berries/replicate, median $=5$ berries) due to the variability in the weights of the cultivated berries $(0.82-4.41 \mathrm{~g} /$ berry, median weight $=3.38 \mathrm{~g})$. However, when exposed to a single berry of each type, that preference was reversed (Fig. 4; $0.14 \pm 0.05$ for wild, $0.86 \pm 0.05$ for cultivated, $\left.\mathrm{p}<0.0001, \mathrm{t}_{12}=4.65\right)$.

\section{Discussion}

By examining the behavior of an agricultural pest in a remote, non-crop setting, we can gain a better understanding of the ecological, behavioral, and physiological plasticity of the insect. First, the high infestation rates (eggs/g fruit) observed in the forested locations suggest these areas are highly suitable to D. suzukiiestablishment. Distribution models for agricultural pests are trained on occurrence data at a regional or global scale, however oftentimes, the available data are collected in a non-random manner. For instance, $D$. suzukii sampling in the United States has mostly occurred in and around susceptible cropping areas. As demonstrated with these data, a common criticism of presence-only models is that they do not adequately extrapolate to novel areas (Elith and Leathwick 2009, Roach et al. 2017). Models trained on D. suzukii occurrence data from North and South America performed worse in this ground truthing exercise than the model trained on a global data set, suggesting improvements could result from more diverse sampling schemes.

Second, wild blackberries were as or more susceptible to D. suzukii oviposition at all ripeness stages than the cultivated blackberries in this study. In an evolutionary sense, cultivated crops are thought to be more exploitable by insect pests than wild relatives due to human-mediated plant domestication selecting against plant defensive traits (Chen et al. 2015, Whitehead et al. 2017). For instance, bitter-tasting secondary metabolites that deter insect feeding are greatly reduced in domesticated plant species (Wink 1988). Generally speaking, domesticated fruits are also much larger than their wild ancestors, and frugivores tend to prefer larger fruits, lending support to this plant domestication-reduced defense hypothesis. Indeed, female $D$. suzukii laid more eggs into cultivated blueberries than wild ones (Rodriguez-Saona et al. 2019). While we also saw the greatest eggs per berry in cultivated ripe and purple fruit, there were significantly more eggs in wild berries after mass was taken into account. Although we do not know how larval competition affects survivability to adulthood in these natural areas, laboratory studies have shown high D. suzukii egg and larval densities can lower mean survivorship, however host quality mediates this effect (Hardin et al. 2015).

A number of factors contribute to oviposition site selection in herbivores, including previous experience, host condition, competition, and predator avoidance (Jaenike 1978, Futuyma and Peterson 1985, Papaj and Prokopy 1989, Carrasco et al. 2015). The higher oviposition we observed in under-ripe wild berries may be, in part, related to shorter ripening times. Wild blackberries are about a quarter the size of the cultivated 'Ouachita' variety sampled here, and exhibited a swifter progression from the blush to ripe stage during collection. ThatD. suzukii can and do develop on a wide variety of host plants and even non-host plants suggests that larval nutritional needs are plastic (Jaramillo et al. 2015, Young et al. 2018, Little et al. 
2020).Drosophila suzukii avoid laying eggs in overripe fruit, presumably to avoid interspecific competition, so it is reasonable to expect a large spillover effect into under-ripe berries if a significant determining factor for fitness is competition. The tradeoff to laying eggs into less-ripe fruit may be small if the appropriate nutrients are gathered as the berry ripens during the same length of time as larvae develop. This strategy might not translate to oviposition in cultivated blackberries because the fruit stay in each ripeness stage for a longer period (see Swoboda-Bhattarai and Burrack 2017). In a sense, thatD. suzukii oviposit more readily into wild fruit suggests that non-domesticated blackberries are more exploitable than their cultivated counterpart.

Another consequence of fruit domestication is a change in fruit ripening windows. Cultivated crops are selected to produce fruit where the majority will ripen around the same time to reduce harvesting labor cost, leaving less diversity among ripeness stages for female oviposition selection (Heiser 1988). In cultivated berries, the number of eggs per berry at each ripeness stage over the season were consistently different from each other, suggesting that oviposition was additive at each stage; the number of eggs per berry increased as a function of time and ripeness. Contrastingly, there was no such pattern in the wild berry samples, which is more indicative of a simultaneous rather than sequential infestation.

Finally, we wanted to assess whether any of the observed difference in oviposition among the cultivation types resulted from host preference. In a direct preference comparison, females preferred laying eggs in cultivated fruit when exposed to a single berry of each type, which may indicate a size or surface area preference given the physical disparity between the two fruit types. However, when offered an equal weight, corresponding to a single cultivated versus several wild berries, females laid more eggs in wild fruit. Long-range perception in oviposition site selection relies heavily on visual cues; at a distance, clusters of berries may appear as a single, large fruit, which could explain why our lab preference results differed when the set-up changed. The observed correlation between apparent fruit size and preference agrees with other visual research on D. suzukii attraction and its effects on oviposition behavior (Rice et al. 2016). Additional experiments that eliminate visual cues will be needed to further assess any preference among cultivated and wild blackberry fruits.

The pattern and timing of infestation we observed in wild-growing berries from natural habitats in the eastern United States is consistent with research in Hawaii, Europe and Japan that trapped adult D. suzukii in montane habitats (Ometto et al. 2013, Mueller 2015, Santioemma et al. 2019). In Japan, while most fruit crops were grown below $600 \mathrm{~m}$, the majority of $D$. suzukii adults were trapped at higher elevations (Ometto et al. 2013). The present study supports this idea, finding a variety of susceptible host plants and high levels of infestation in the most abundant resource, wild blackberry. We observed that once fruit began to ripen, sometime between the green and blush stage, the berries were exploited for oviposition by D. suzukiifemales.

Given this information about the presence of established populations of D. suzukii in remote, montane regions of the southern Appalachian Mountains, several new research questions arise. Within the wooded landscape, D. suzukii may be affecting the local food web by utilizing wild blackberries upstream of other organisms. What effect does this invasive pest have on other blackberry feeders such as birds, bears, or other invertebrates? In terms of agroecosystem impact, do these types of forest populations serve as a potential source for regional migration into crop habitats? No seasonal migration pattern has been established for D. suzukii , though marked adults have been caught at distances in excess of four times their flight capacity (Tait et al. 2018, Wong et al. 2018). The full extent of current and future impacts of D. suzukii in croplands and beyond has yet to be fully realized.

\section{Author contributions}

J.E.E. and H.J.B. conceived of the study and analyzed the data. J.E.E. conducted the experiment and wrote the manuscript. H.J.B. provided research funds and edited the manuscript.

Statement on inclusion: Our study was conducted on federal, state, and private property in the state where the authors resided. With each location, we discussed the need and goals for such research with current land managers, and only proceeded with data collection once formal permission was received. All parties were 
supportive of this project.

\section{Acknowledgements}

The authors would like to thank Aurora Toennisson for their assistance with sample processing, the Schal lab for feedback on research protocols, Burrack lab members for manuscript suggestions, Keck Center for research funding, the US National Forest Service and the Grandfather Mountain Stewardship Foundation for collection permission, and NSF-IGERT (grant number DGE-1068676) for fellowship support (JEE), and the USDA NIFA OREI program (grant numbers 2018-02859 and 2015-07403) for research support. The authors declare no conflict of interest.

\section{Data Accessibility Statement}

Data files from this manuscript will be deposited in the Dryad database system available at [url to be determined]. Data can also be requested through the authors.

\section{References}

Ballman, E. S. \& Drummond, F. A. (2017). Infestation of wild fruit byDrosophila suzukii surrounding Maine wild blueberry fields. Journal of Agricultural and Urban Entomology , 33 , 61-70. https://doi.org/10.3954/1523-5475-33.1.61

Barringer, L. \& Ciafré, C. M. (2020). Worldwide feeding host plants of Spotted Lanternfly, with significant additions from North America. Environmental Entomology , 49 , 999-1011. https://doi.org/10.1093/ee/nvaa093

Bellamy, D. E., Sisterson, M. S. \& Walse, S. S. (2013). Quantifying host potentials: indexing postharvest fresh fruits for spotted wing drosophila, Drosophila suzukii . PLoS One , 8 , e61227. https://doi.org/10.1371/journal.pone.0061227

Bernardi, D., Andreazza, F., Botton, M., Baronio, C. A. \& Nava, D. E. (2017). Susceptibility and interactions of Drosophila suzukii andZaprionus indianus (Diptera: Drosophilidae) in damaging strawberry. Neotropical Entomology , 46 , 1-7. https://doi.org/10.1007/s13744-016-0423-9

Calabria, G., Máca, J., Bächli, G., Serra, L. \& Pascual, M. (2012). First records of the potential pest species Drosophila suzukii(Diptera: Drosophilidae) in Europe. Journal of Applied Entomology , 136 , 139147. https://doi.org/10.1111/j.1439-0418.2010.01583.x

Carrasco, D., Larsson, M. C. \& Anderson, P. (2015). Insect host plant selection in complex environments. Current Opinion in Insect Science, 8 , 1-7. https://doi.org/10.1016/j.cois.2015.01.014

Chen, Y. H., Gols, R. \& Benrey, B. (2015). Crop domestication and its impact on naturally selected trophic interactions. Annual Review of Entomology , 60 , 35-58. https://doi.org/10.1146/annurev-ento-010814-020601

Compton, S. G. (2002). Sailing with the wind: dispersal by small flying insects. In J. M. Powell, R. E. Kenward \& R. S. Hails (Eds.),Dispersal Ecology , (pp.113-133). Blackwell Publishing.

de la Vega, G. J. \& Corley, J. C. (2019). Drosophila suzukii(Diptera: Drosophilidae) distribution modelling improves our understanding of pest range limits. International Journal of Pest Management, 65 , 217-227. https://doi.org/10.1080/09670874.2018.1547460

Deprá, M., Poppe, J. L., Schmitz, H. J., De Toni, D. C. \& Valente, V. L. (2014). The first records of the invasive pest Drosophila suzukii in the South American continent. Journal of Pest Science , 87, 379-383. https://doi.org/10.1007/s10340-014-0591-5

Diepenbrock, L. M., Swoboda-Bhattarai, K. A. \& Burrack, H. J. (2016). Ovipositional preference, fidelity, and fitness of Drosophila suzukii in a co-occurring crop and non-crop host system. Journal of Pest Science , 89 , 761-769. https://doi.org/10.1007/s10340-016-0764-5 
dos Santos, L. A., Mendes, M. F., Krüger, A. P., Blauth, M. L., Gottschalk, M. S. \& Garcia, F. R. (2017). Global potential distribution of Drosophila suzukii (Diptera, Drosophilidae). PLoS One, 12, e0174318. https://doi.org/10.1371/journal.pone.0174318

Elith, J. \& Leathwick, J. R. (2009). Species distribution models: ecological explanation and prediction across space and time. Annual Review of Ecology, Evolution, and Systematics , 40 , 677-697. https://doi.org/10.1146/annurev.ecolsys.110308.120159

Elsensohn, J. E. \& Loeb, G. M. (2018). Non-crop host sampling yields insights into small-scale population dynamics of Drosophila suzukii (Matsumura). Insects , 9 , 5. https://doi.org/10.3390/insects9010005

Fitzpatrick, M. C., Weltzin, J. F., Sanders, N. J. \& Dunn, R. R. (2007). The biogeography of prediction error: why does the introduced range of the fire ant over-predict its native range?. Global Ecology and Biogeography , 16 , 24-33. https://doi.org/10.1111/j.1466-8238.2006.00258.x

Fraimout, A. \& Monnet, A. C. (2018). Accounting for intraspecific variation to quantify niche dynamics along the invasion routes ofDrosophila suzukii. Biological Invasions , 20 , 2963-2979. https://doi.org/10.1007/s10530-018-1750-z

Futuyma, D. J. \& Peterson, S. C. (1985). Genetic variation in the use of resources by insects. Annual Review of Entomology , 30 , 217-238.

Gutierrez, A. P., Ponti, L. \& Dalton, D. T. (2016). Analysis of the invasiveness of spotted wing Drosophila (Drosophila suzukii) in North America, Europe, and the Mediterranean Basin. Biological Invasions , 18 , 3647-3663. https://doi.org/10.1007/s10530-016-1255-6

Hardin, J. A., Kraus, D. A. \& Burrack, H. J. (2015). Diet quality mitigates intraspecific larval competition in Drosophila suzukii . Entomologia Experimentalis et Applicata , 156 , 59-65. https://doi.org/10.1111/eea.12311

Hassani, I. M., Behrman, E. L., Prigent, S. R., Gidaszewski, N., Ravaomanarivo, L. R., Suwalski, A., Debat, V., David, J. R. \& Yassin, A. (2020). First occurrence of the pest Drosophila suzukii(Diptera: Drosophilidae) in the Comoros Archipelago (Western Indian Ocean). African Entomology , 28 , 78-83. https://doi.org/10.4001/003.028.0078

Hauser, M. (2011). A historic account of the invasion ofDrosophila suzukii (Matsumura)(Diptera: Drosophilidae) in the continental United States, with remarks on their identification. Pest Management Science , 67 , 1352-1357. https://doi.org/10.1002/ps.2265

Heiser, C. B. (1988). Aspects of unconscious selection and the evolution of domesticated plants. Euphytica , 37, 77-81.

Hoelscher, C. E. (1967). Wind dispersal of brown soft scale crawlers, Coccus hesperidum (Homoptera: Coccidae), and Texas citrus mites, Eutetranychus banksi (Acarina: Tetranychidae) from Texas citrus. Annals of the Entomological Society of America ,60 , 673-678. https://doi.org/10.1093/aesa/60.3.673

Jaenike, J. (1978). On optimal oviposition behavior in phytophagous insects. Theoretical Population Biology , 14 , 350-356. https://doi.org/10.1016/0040-5809(78)90012-6

Jaramillo, S. L., Mehlferber, E. \& Moore, P. J. (2015). Life-history trade-offs under different larval diets in Drosophila suzukii(Diptera: Drosophilidae). Physiological Entomology , 40 , 2-9. https://doi.org/10.1111/phen.12082

Kamiyama, M. T. \& Guedot, C. (2019). Varietal and developmental susceptibility of tart cherry (Rosales: Rosaceae) to Drosophila suzukii (Diptera: Drosophilidae). Journal of Economic Entomology , 112 , 17891797. https://doi.org/10.1093/jee/toz102

Kennedy, G. G. \& Storer, N. P. (2000). Life systems of polyphagous arthropod pests in temporally unstable cropping systems. Annual Review of Entomology , 45 , 467-493. 
https://doi.org/10.1146/annurev.ento.45.1.467

Klick, J., Yang, W. Q., Walton, V. M., Dalton, D. T., Hagler, J. R., Dreves, A. J., Lee, J. C. \& Bruck, D. J. (2016). Distribution and activity of Drosophila suzukii in cultivated raspberry and surrounding vegetation. Journal of Applied Entomology , 140 , 37-46. https://doi.org/10.1111/jen.12234

Lee, J. C., Bruck, D. J., Curry, H., Edwards, D., Haviland, D. R., Van Steenwyk, R. A. \& Yorgey, B. M. (2011). The susceptibility of small fruits and cherries to the spotted-wing drosophila, Drosophila suzukii .Pest Management Science, 67, 1358-1367. https://doi.org/10.1002/ps.2225

Lee, J. C., Dreves, A. J., Cave, A. M., Kawai, S., Isaacs, R., Miller, J. C., Van Timmeren, S. \& Bruck, D. J. (2015). Infestation of wild and ornamental noncrop fruits by Drosophila suzukii (Diptera: Drosophilidae). Annals of the Entomological Society of America , 108 , 117-129. https://doi.org/10.1093/aesa/sau014

Little, C. M., Chapman, T. W. \& Hillier, N. K. (2020). Plasticity is key to success of Drosophila suzukii (Diptera: Drosophilidae) invasion. Journal of Insect Science , 20 , 5. https://doi.org/10.1093/jisesa/ieaa034

Mazzi, D. \& Dorn, S. (2012). Movement of insect pests in agricultural landscapes. Annals of Applied Biology , 160 , 97-113. https://doi.org/10.1111/j.1744-7348.2012.00533.x

Mitsui, H., Beppu, K. \& Kimura, M. T. (2010). Seasonal life cycles and resource uses of flower-and fruitfeeding drosophilid flies (Diptera: Drosophilidae) in central Japan. Entomological Science , 13 , 60-67. https://doi.org/10.1111/j.1479-8298.2010.00372.x

Moser, D., Drapela, T., Zaller, J. G. \& Frank, T. (2009). Interacting effects of wind direction and resource distribution on insect pest densities. Basic and Applied Ecology , 10 , 208-215. https://doi.org/10.1016/j.baae.2008.03.008

Mueller, M. C. (2015). Islands within islands: The effects of habitat fragmentation, novel community interactions, and climate on HawaiianDrosophila populations. Masters thesis. University of Hawai'i, Hilo.

Ometto, L., Cestaro, A., Ramasamy, S., Grassi, A., Revadi, S., Siozios, S., Moretto, M., Fontana, P., Varotto, C., Pisani, D. \& Dekker, T. (2013). Linking genomics and ecology to investigate the complex evolution of an invasive Drosophila pest. Genome Biology and Evolution , 5 , 745-757. https://doi.org/10.1093/gbe/evt034

Orsted, I. V. \& Orsted, M. (2019). Species distribution models of the Spotted Wing Drosophila (Drosophila suzukii , Diptera: Drosophilidae) in its native and invasive range reveal an ecological niche shift. Journal of Applied Ecology , 56 , 423-435. https://doi.org/10.1111/1365-2664.13285

Panel, A. D., Zeeman, L., Van der Sluis, B. J., Van Elk, P., Pannebakker, B. A., Wertheim, B. \& Helsen, H. H. (2018). OverwinteredDrosophila suzukii are the main source for infestations of the first fruit crops of the season. Insects , 9 , 145. https://doi.org/10.3390/insects9040145

Papaj, D. R. \& Prokopy, R. J. (1989). Ecological and evolutionary aspects of learning in phytophagous insects. Annual Review of Entomology , 34, 315-350.

Parchami-Araghi, M., Gilasian, E. \& Keyhanian, A. A. (2015). Spotted wing drosophila, Drosophila suzukii (Matsumura)(Dip.: Drosophilidae), an invasive fruit pest new to the middle East and Iran. Drosophila Information Service, 98 , 59-60.

Pelton, E., Gratton, C., Isaacs, R., Van Timmeren, S., Blanton, A. \& Guedot, C. (2016). Earlier activity of Drosophila suzukii in high woodland landscapes but relative abundance is unaffected. Journal of Pest Science, 89 , 725-733. https://doi.org/10.1007/s10340-016-0733-z

Powell, R. A. \& Seaman, D. E. (1990). Production of important black bear foods in the southern Appalachians. Bears: Their Biology and Management , 8 , 183-187.

Poyet, M., Eslin, P., Heraude, M., Le Roux, V., Prevost, G., Gibert, P. \& Chabrerie, O. (2014). Invasive host for invasive pest: when the Asiatic cherry fly (Drosophila suzukii) meets the American black cherry (Prunus 
serotina ) in Europe. Agricultural and Forest Entomology , 16 , 251-259. https://doi.org/10.1111/afe.12052

Rand, T. A., Tylianakis, J. M. \& Tscharntke, T. (2006). Spillover edge effects: the dispersal of agriculturally subsidized insect natural enemies into adjacent natural habitats. Ecology Letters , 9 , 603-614. https://doi.org/10.1111/j.1461-0248.2006.00911.x

Rice, K. B., Short, B. D., Jones, S. K. \& Leskey, T. C. (2016). Behavioral responses of Drosophila suzukii (Diptera: Drosophilidae) to visual stimuli under laboratory, semifield, and field conditions. Environmental Entomology , 45 , 1480-1488. https://doi.org/10.1093/ee/nvw123

Roach, N. S., Hunter, E. A., Nibbelink, N. P. \& Barrett, K. (2017). Poor transferability of a distribution model for a widespread coastal marsh bird in the southeastern United States. Ecosphere , 8 , e01715. https://doi.org/10.1002/ecs2.1715

Rodriguez-Saona, C., Cloonan, K. R., Sanchez-Pedraza, F., Zhou, Y., Giusti, M. M. \& Benrey, B. (2019). Differential susceptibility of wild and cultivated blueberries to an invasive frugivorous pest. Journal of Chemical Ecology , 45 , 286-297. https://doi.org/10.1007/s10886-018-1042-1

Rossi-Stacconi, M. V., Kaur, R., Mazzoni, V., Ometto, L., Grassi, A., Gottardello, A., Rota-Stabelli, O. \& Anfora, G. (2016). Multiple lines of evidence for reproductive winter diapause in the invasive pestDrosophila suzukii : useful clues for control strategies. Journal of Pest Science , 89 , 689-700. https://doi.org/10.1007/s10340-016-0753-8

Sakai, A. K., Allendorf, F. W., Holt, J. S., Lodge, D. M., Molofsky, J., With, K. A., Baughman, S., Cabin, R. J., Cohen, J. E., Ellstrand, N. C. \& McCauley, D. E. (2001). The population biology of invasive species. Annual Review of Ecology and Systematics , 32 , 305-332. https://doi.org/10.1146/annurev.ecolsys.32.081501.114037

Santoiemma, G., Mori, N., Tonina, L. \& Marini, L. (2018). Semi-natural habitats boost Drosophila suzukii populations and crop damage in sweet cherry. Agriculture, Ecosystems $\mathscr{E}$ Environment, 257, 152-158. https://doi.org/10.1016/j.agee.2018.02.013

Santoiemma, G., Fioretto, D., Corcos, D., Mori, N. \& Marini, L. (2019). Spatial synchrony in Drosophila suzukii population dynamics along elevational gradients. Ecological Entomology , 44 , 182-189. https://doi.org/10.1111/een.12688

Sarquis, J. A., Cristaldi, M. A., Arzamendia, V., Bellini, G. \& Giraudo, A.R. (2018). Species distribution models and empirical test: Comparing predictions with well-understood geographical distribution of Bothrops alternatus in Argentina. Ecology and Evolution , 8 , 10497-10509. https://doi.org/10.1002/ece3.4517

Swoboda-Bhattarai, K.A. \& Burrack, H.J. (2015). Drosophila suzukii infestation in ripe and ripening caneberries. Acta Horticulturae , 1133 , 419-430. https://doi.org/10.17660/ActaHortic.2016.1133.65

Tait, G., Grassi, A., Pfab, F., Crava, C. M., Dalton, D. T., Magarey, R., Ometto, L., Vezzulli, S., RossiStacconi, M. V., Gottardello, A. \& Pugliese, A. (2018). Large-scale spatial dynamics of Drosophila suzukii in Trentino, Italy. Journal of Pest Science, 91 , 1213-1224. https://doi.org/10.1007/s10340-018-0985-x

Teulon, D. A. J., Leskey, T. C. \& Cameron, E. A. (1998). Pear thrips Taeniothrips inconsequens (Thysanoptera: Thripidae) life history and population dynamics in sugar maple in Pennsylvania. Bulletin of Entomological Research , 88 , 83-92. https://doi.org/10.1017/S0007485300041584

Tonina, L., Mori, N., Sancassani, M., Dall'Ara, P. \& Marini, L. (2018). Spillover of Drosophila suzukii between noncrop and crop areas: implications for pest management. Agricultural and Forest Entomology , 20 , 575-581. https://doi.org/10.1111/afe.12290

Wallingford, A. K., Rice, K. B., Leskey, T. C. \& Loeb, G. M. (2018). Overwintering behavior of Drosophila suzukii, and potential springtime diets for egg maturation. Environmental Entomology , 47 , 1266-1273. https://doi.org/10.1093/ee/nvy115 
Ward, L.K. \& Spalding, D.F. (1993). Phytophagous British insects and mites and their food-plant families: total numbers and polyphagy. Biological Journal of the Linnean Society , 49 , 257-276.

Weakley, A. S. (2006). Flora of the Carolinas, Virginia, Georgia and surrounding areas. University of North Carolina at Chapel Hill. https://herbarium.unc.edu

Whitehead, S. R., Turcotte, M. M. \& Poveda, K. (2017). Domestication impacts on plant-herbivore interactions: a meta-analysis. Philosophical Transactions of the Royal Society B: Biological Sciences , 372 , 20160034. https://doi.org/10.1098/rstb.2016.0034

Wink, M. (1988). Plant breeding: importance of plant secondary metabolites for protection against pathogens and herbivores. Theoretical and Applied Genetics , 75 , 225-233.

Wong, J. S., Cave, A. C., Lightle, D. M., Mahaffee, W. F., Naranjo, S. E., Wiman, N. G., Woltz, J. M. \& Lee, J. C. (2018). Drosophila suzukii flight performance reduced by starvation but not affected by humidity. Journal of Pest Science, 91 , 1269-1278. https://doi.org/10.1007/s10340-018-1013-x

Wright, J. W., Davies, K. F., Lau, J. A., McCall, A. C. \& McKay, J. K. (2006). Experimental verification of ecological niche modeling in a heterogeneous environment. Ecology , 87, 2433-2439. https://doi.org/10.1890/0012-9658(2006)87[2433:EVOENM]2.0.CO;2

Young, Y., Buckiewicz, N. \& Long, T. A. (2018). Nutritional geometry and fitness consequences in Drosophila suzukii, the Spotted-Wing Drosophila. Ecology and Evolution , 8 , 2842-2851. https://doi.org/10.1002/ece3.3849

\section{Figures and Tables}

\section{Hosted file}

image1.emf available at https://authorea.com/users/439720/articles/540583-plasticityin-oviposition-and-foraging-behavior-in-the-invasive-pest-drosophila-suzukii-acrossnatural-and-agricultural-landscapes

\section{Hosted file}

image2.emf available at https://authorea.com/users/439720/articles/540583-plasticityin-oviposition-and-foraging-behavior-in-the-invasive-pest-drosophila-suzukii-acrossnatural-and-agricultural-landscapes

Figure 1. a) Mean +- SEM number of D. suzukii eggs/berry averaged across all collection locations and dates. Cultivated purple and ripe fruit contain more eggs than the wild type. b) Mean +- SEM eggs/gram of fruit show higher infestation levels in wild fruit. Raw means are presented, with adjusted means used for mean separation. Means within each pane indicated by the same letter are not significantly different from each other (alpha $=0.05)$.

\section{Hosted file}

image3.emf available at https://authorea.com/users/439720/articles/540583-plasticityin-oviposition-and-foraging-behavior-in-the-invasive-pest-drosophila-suzukii-acrossnatural-and-agricultural-landscapes

\section{Hosted file}

image4.emf available at https://authorea.com/users/439720/articles/540583-plasticityin-oviposition-and-foraging-behavior-in-the-invasive-pest-drosophila-suzukii-acrossnatural-and-agricultural-landscapes

Figure 2. Weekly infestation rates +- SEM across both years for a) cultivated berries and b) wild berries. Symbols denote sample points; not all ripeness stages were available to be collected each week. Raw means 
are presented, with adjusted means used for mean separation. Means within the same quadrangle are not significantly different from each other (alpha $=0.05$ ).

\section{Hosted file}

image5.emf available at https://authorea.com/users/439720/articles/540583-plasticityin-oviposition-and-foraging-behavior-in-the-invasive-pest-drosophila-suzukii-acrossnatural-and-agricultural-landscapes

Figure 3. Weekly infestation averages in the 2018 elevational transects. Means within the same elevation indicated by the same letter are not significantly different from each other, alpha $=0.05$. NS $=$ zero or fewer than 10 berries were sampled at that collection point.

\section{Hosted file}

image6.emf available at https://authorea.com/users/439720/articles/540583-plasticityin-oviposition-and-foraging-behavior-in-the-invasive-pest-drosophila-suzukii-acrossnatural-and-agricultural-landscapes

Figure 4. Mean proportion of eggs +- SEM laid into cultivated or wild-grown blackberries. Females show opposite oviposition preferences when given an equal mass or equal number of cultivated and wild fruit. Student t-test: equal mass $\mathrm{t}_{13}=5.72$; equal number $\mathrm{t}_{12}=-4.65$, alpha $=0.05$.

Table 1. Average percentage of berries per sample that were infested with at least one egg for each cultivation and ripeness type. Mean separations were determined by ANOVA followed by Tukey Kramer adjustment. Means followed by the same letter are not significantly different from each other, alpha $=0.05$.

\begin{tabular}{lllll}
\hline Growth type & Ripeness stage & No. collection points & Total N & Mean percentage infestation \pm SE \\
\hline Wild & Green & 8 & 119 & $55.7 \pm 16.0 \mathrm{ab}$ \\
Wild & Blush & 19 & 350 & $81.0 \pm 4.6 \mathrm{bc}$ \\
Wild & Red & 20 & 378 & $93.6 \pm 2.8 \mathrm{bd}$ \\
Wild & Purple & 29 & 496 & $96.4 \pm 2.5 \mathrm{bd}$ \\
Wild & Ripe & 30 & 562 & $98.6 \pm 0.7 \mathrm{~d}$ \\
Cultivated & Blush & 4 & 80 & $28.8 \pm 10 \mathrm{a}$ \\
Cultivated & Red & 5 & 100 & $82.0 \pm 4.1 \mathrm{bd}$ \\
Cultivated & Purple & 5 & 101 & $94.0 \pm 4.8 \mathrm{bd}$ \\
Cultivated & Ripe & 10 & 185 & $98.0 \pm 1.5 \mathrm{~cd}$ \\
\hline
\end{tabular}

\section{Supplemental Information}

Table S1. Collection locations with corresponding habitat and elevation data.

\begin{tabular}{lllllll}
\hline Location & Habitat & Zone & Longitude & Latitude & Elevation $(\mathbf{m})$ & Years sampled \\
\hline Southern Nantahala & woods & $17 \mathrm{~S}$ & $83^{\circ} 01^{\prime} 20.4^{\prime \prime} \mathrm{W}$ & $35^{\circ} 09^{\prime} 19.5^{\prime \prime} \mathrm{N}$ & 1230 & 2017 \\
Southern Nantahala & woods & $17 \mathrm{~S}$ & $83^{\circ} 17^{\prime} 16.5^{\prime \prime} \mathrm{W}$ & $35^{\circ} 04^{\prime} 33.7^{\prime \prime} \mathrm{N}$ & 1330 & 2017 \\
Joyce Kilmer & woods & $17 \mathrm{~S}$ & $83^{\circ} 58^{\prime} 41.81^{\prime \prime} \mathrm{W}$ & $35^{\circ} 21^{\prime} 50.89^{\prime \prime} \mathrm{N}$ & 1430 & 2017,2018 \\
Joyce Kilmer & woods & $17 \mathrm{~S}$ & $83^{\circ} 59^{\prime} 19.09^{\prime \prime} \mathrm{W}$ & $35^{\circ} 22^{\prime} 31.46^{\prime \prime} \mathrm{N}$ & 1630 & 2017,2018 \\
Joyce Kilmer & roadside & $16 \mathrm{~S}$ & $84^{\circ} 01^{\prime} 28.0^{\prime \prime} \mathrm{W}$ & $35^{\circ} 20^{\prime} 16.7^{\prime \prime} \mathrm{N}$ & 1345 & 2017 \\
Joyce Kilmer & roadside & $16 \mathrm{~S}$ & $84^{\circ} 00^{\prime} 09.1^{\prime \prime} \mathrm{W}$ & $35^{\circ} 18^{\prime} 14.3^{\prime \prime} \mathrm{N}$ & 1630 & 2017 \\
Joyce Kilmer & roadside & $16 \mathrm{~S}$ & $84^{\circ} 02^{\prime} 07.7^{\prime \prime} \mathrm{W}$ & $35^{\circ} 20^{\prime} 42.9^{\prime \prime} \mathrm{N}$ & 1360 & 2017 \\
Joyce Kilmer & roadside & $17 \mathrm{~S}$ & $84^{\circ} 01^{\prime} 18.8^{\prime \prime} \mathrm{W}$ & $35^{\circ} 19^{\prime} 03.6^{\prime \prime} \mathrm{N}$ & 1085 & 2017 \\
Joyce Kilmer & roadside & $17 \mathrm{~S}$ & $84^{\circ} 02^{\prime} 07.7^{\prime \prime} \mathrm{W}$ & $35^{\circ} 20^{\prime} 42.9^{\prime \prime} \mathrm{N}$ & 1500 & 2017 \\
Joyce Kilmer & roadside & $17 \mathrm{~S}$ & $83^{\circ} 58^{\prime} 57.1^{\prime \prime} \mathrm{W}$ & $3^{\circ} 19^{\prime} 14.2^{\prime \prime} \mathrm{N}$ & 1260 & 2017 \\
Joyce Kilmer & roadside & $17 \mathrm{~S}$ & $83^{\circ} 49^{\prime} 34.1^{\prime \prime} \mathrm{W}$ & $35^{\circ} 20^{\prime} 07.2^{\prime \prime} \mathrm{N}$ & 610 & 2017,2018
\end{tabular}




\begin{tabular}{lllllll}
\hline Location & Habitat & Zone & Longitude & Latitude & Elevation $(\mathbf{m})$ & Years sampled \\
\hline Research station & farm & $17 \mathrm{~S}$ & $81^{\circ} 19^{\prime} 01.5^{\prime \prime} \mathrm{W}$ & $36^{\circ} 23^{\prime} 59.3^{\prime \prime} \mathrm{N}$ & 900 & 2017,2018 \\
Research station & farm & $17 \mathrm{~S}$ & $82^{\circ} 33^{\prime} 29.7^{\prime \prime} \mathrm{W}$ & $35^{\circ} 25^{\prime} 05.9 ” \mathrm{~N}$ & 610 & 2017 \\
Cherokee & woods & $17 \mathrm{~S}$ & $81^{\circ} 49^{\prime} 50.2^{\prime \prime} \mathrm{W}$ & $36^{\circ} 05^{\prime} 49.6^{\prime \prime} \mathrm{N}$ & 1630 & 2017 \\
Cherokee & woods & $17 \mathrm{~S}$ & $81^{\circ} 50^{\prime} 13.6^{\prime \prime} \mathrm{W}$ & $36^{\circ} 05^{\prime} 23.8^{\prime \prime} \mathrm{N}$ & 1430 & 2017 \\
Joyce Kilmer & woods & $17 \mathrm{~S}$ & $83^{\circ} 59^{\prime} 3.62^{\prime \prime} \mathrm{W}$ & $35^{\circ} 22^{\prime} 50.16^{\prime \prime} \mathrm{N}$ & 1480 & 2018 \\
Joyce Kilmer & woods & $17 \mathrm{~S}$ & $83^{\circ} 59^{\prime} 12.08^{\prime \prime} \mathrm{W}$ & $35^{\circ} 22^{\prime} 41.74 \prime \mathrm{N}$ & 1530 & 2018 \\
Joyce Kilmer & woods & $17 \mathrm{~S}$ & $83^{\circ} 59^{\prime} 18.13^{\prime \prime} \mathrm{W}$ & $35^{\circ} 22^{\prime} 33.49^{\prime \prime} \mathrm{N}$ & 1580 & 2018 \\
\hline
\end{tabular}

Table S2. Combined season long average eggs per berry in samples of wild-grown blackberries collected in and around JKWA.

\begin{tabular}{|c|c|c|c|c|}
\hline Ripeness stage & $\begin{array}{l}\text { Mean } \pm \mathrm{SE} \\
\text { Roadside }\end{array}$ & $\mathbf{N}$ & $\begin{array}{l}\text { Mean } \pm \text { SE } \\
\text { Woods }\end{array}$ & $\mathbf{N}$ \\
\hline Green & $4.02 \pm 0.54$ & 51 & $4.88 \pm 1.0$ & 33 \\
\hline Blush & $2.17 \pm 0.33$ & 46 & $5.42 \pm 0.26$ & 254 \\
\hline Red & $6.67 \pm 0.45$ & 148 & $5.80 \pm 0.32$ & 196 \\
\hline Purple & $9.16 \pm 0.46$ & 177 & $8.69 \pm 0.35$ & 245 \\
\hline Ripe & $9.25 \pm 0.40$ & 178 & $11.03 \pm 0.39$ & 253 \\
\hline
\end{tabular}

Table S3 . Plant species sampled at the ripe stage during study period. Percent infestation is defined as the percentage of berries containing at least one egg.

\begin{tabular}{lllll}
\hline Species & Mean eggs per berry \pm SE & Mean eggs per gram \pm SE & N & Percent infestation \\
\hline Vaccinium erythrocarpum & $4.91 \pm 0.32$ & $21.16 \pm 1.37$ & 60 & $100 \%$ \\
Vaccinium pallidum & $5.9 \pm 0.61$ & $20.03 \pm 2.06$ & 20 & $100 \%$ \\
Phytolacca americana & $12.4 \pm 0.8$ & $34.51 \pm 2.24$ & 30 & $100 \%$ \\
Maianthemum racemosum & $0.33 \pm 0.17$ & $1.81 \pm 0.94$ & 21 & $19 \%$ \\
Polygonatum biflorum & $0 \pm 0$ & $0 \pm 0$ & 18 & $0 \%$ \\
\hline
\end{tabular}

\section{Hosted file}

image7.emf available at https://authorea.com/users/439720/articles/540583-plasticityin-oviposition-and-foraging-behavior-in-the-invasive-pest-drosophila-suzukii-acrossnatural-and-agricultural-landscapes

Figure S1 . Weekly average percentage of fruit infested per sample date in a) cultivated or b) wild-grown blackberries. Symbol markers indicate collection dates for a specific ripeness stage. . 